\title{
Clinical utility of polyethylene glycol conjugated granulocyte colony-stimulating factor (PEG-G-CSF) for preventing severe neutropenia in metastatic colorectal cancer patients treated with FOLFOXIRI plus bevacizumab: a single-center retrospective study
}

Yusuke Kitagawa ${ }^{\dagger}$, Hiroki Osumi ${ }^{\dagger}$, Eiji Shinozaki ${ }^{*}$, Yumiko Ota, Izuma Nakayama, Takeshi Suzuki, Takeru Wakatsuki, Mariko Ogura, Akira Ooki, Daisuke Takahari, Mitsukuni Suenaga, Keisho Chin and Kensei Yamaguchi

\begin{abstract}
Background: This study aimed to evaluate the efficacy and the safety of polyethylene glycol conjugated granulocyte colony-stimulating factor (PEG-G-CSF) for preventing neutropenia in metastatic colorectal cancer (mCRC) patients that received fluorouracil, leucovorin, oxaliplatin, and irinotecan (FOLFOXIRI) plus bevacizumab (Bev) in clinical practice.

Methods: We retrospectively analyzed mCRC patients who received FOLFOXIRI plus Bev between December 2015 and December 2017. We evaluated the efficacy of PEG-G-CSF as preventing or treating grade 3 or 4 neutropenia, the overall response rate (ORR) according to the Response Evaluation Criteria in Solid Tumors version 1.1, progression-free survival (PFS), overall survival (OS), and adverse events of FOLFOXIRI plus Bev based on the Common Terminology Criteria for Adverse Events version 4.0.

Results: A total of 26 patients (median age 53.5 years) were included. The ORR rate was 65.3\%, the median PFS was 9.6 months (7.2-16.9), and the median OS was 24.2 months (13.6-NA). Grade 3 or 4 neutropenia occurred in 53.8\% of the patients, and febrile neutropenia occurred in 7.7\%. PEG-G-CSF was given to $77.0 \%$ of the patients, including prophylactically $(n=9)$ and after the development of grade 3 or 4 neutropenia $(n=11)$. No patients experienced grade 3 or 4 neutropenia after the administration of PEG-G-CSF. In seven of the nine patients who received PEG-G-CSF prophylactically (77.8\%), no dose adjustment was required.
\end{abstract}

Conclusions: PEG-G-CSF is useful in preventing severe neutropenia in mCRC patients treated with FOLFOXIRI plus Bev.

Keywords: FOLFOXIRI plus bevacizumab, Neutropenia, Polyethylene glycol conjugated granulocyte colony-stimulating factor

\footnotetext{
* Correspondence: eiji.shinozaki@jfcr.or.jp

${ }^{\dagger}$ Yusuke Kitagawa and Hiroki Osumi contributed equally to this work. Department of Gastroenterology, The Cancer Institute Hospital, Japanese Foundation for Cancer Research, 3-8-31 Ariake, Koto-ku, Tokyo 135-8550, Japan
}

C The Author(s). 2020 Open Access This article is licensed under a Creative Commons Attribution 4.0 International License, which permits use, sharing, adaptation, distribution and reproduction in any medium or format, as long as you give appropriate credit to the original author(s) and the source, provide a link to the Creative Commons licence, and indicate if changes were made. The images or other third party material in this article are included in the article's Creative Commons licence, unless indicated otherwise in a credit line to the material. If material is not included in the article's Creative Commons licence and your intended use is not permitted by statutory regulation or exceeds the permitted use, you will need to obtain permission directly from the copyright holder. To view a copy of this licence, visit http://creativecommons.org/licenses/by/4.0/. The Creative Commons Public Domain Dedication waiver (http://creativecommons.org/publicdomain/zero/1.0/) applies to the data made available in this article, unless otherwise stated in a credit line to the data. 


\section{Background}

Recently, combination chemotherapy of cytotoxic agents such as irinotecan, oxaliplatin, and fluorouracil, and molecular targeted-drugs, including anti-vascular endothelial growth factor antibody and anti-epidermal growth factor antibody have extended the overall survival (OS) of patients with metastatic colorectal cancer (mCRC) [1]. The efficacy of fluorouracil, leucovorin, oxaliplatin, and irinotecan (FOLFOXIRI) for $\mathrm{mCRC}$ patients in terms of overall response rate (ORR), progression-free survival (PFS), and OS was confirmed by several studies [2]. The benefit of adding bevacizumab (Bev) to the FOLFOXIRI regimen has also been demonstrated and the use of FOLFOXIRI plus Bev as an upfront treatment for $\mathrm{mCRC}$ patients is currently widely used $[3,4]$. In the Pan-Asian adopted European Society for Medical Oncology (ESMO) consensuses guidelines, FOLFOXIRI plus Bev is recommended as first-line cytoreduction chemotherapy in "fit" $\mathrm{mCRC}$ patients with right-sided primary tumor location or for those with the BRAF V600E mutation [5]. FOLFOXIRI plus Bev is also one of the alternative treatment options of first-line chemotherapy of $\mathrm{mCRC}$ listed in several treatment guidelines, including the Japanese Society for Cancer of the Colon and Rectum Guidelines 2019 [6]. Furthermore, the MEBGEN RAS$\mathrm{KET}^{\mathrm{TM}}-\mathrm{B}$ kit was recently approved in Japan for detecting mCRC patients with the BRAF V600E mutation [7]. Therefore, it is expected that the number of patients treated with FOLFOXIRI plus Bev will increase.

With regard to adverse events of FOLFOXIRI plus Bev, grade 3 or higher neutropenia or febrile neutropenia (FN) frequently occur. Several studies have shown that approximately $50 \%$ of patients experience grade 3 or higher neutropenia [3, 8-11]. In a Japanese phase 2 trial of FOLFOXIRI plus Bev for mCRC, Grade 3 or higher neutropenia and FN occurred in 72.5 and $21.7 \%$, respectively [12]. The American Society of Clinical oncology practice guidelines recommend the prophylactic use of granulocyte colony stimulating factor (G-CSF) when the risk of FN in approximately $20 \%$ or higher [13]. Thus, we consider prophylactic G-CSF to be suitable for Japanese patients treated with FOLFOXIRI plus Bev. However, a dose adjustment of the chemotherapy is often required, and the management of neutropenia is often inadequate, even if G-CSF is administered. Polyethylene glycolconjugated G-CSF (PEG-G-CSF), which is characterized as having an increased circulating half-life, has the potential to shorten the duration and severity of neutropenia. However, while the addition of PEG-G-CSF with FOLFOXIRI plus Bev may be useful in preventing severe neutropenia or FN, there are currently few reports evaluating the efficacy of the PEGG-CSF for neutropenia in mCRC patients administered FOLFOXIRI plus Bev and in the safety of PEG-G-CSF administered every 2 weeks. The current study aimed to evaluate the efficacy and safety of the PEG-G-CSF for preventing neutropenia in mCRC patients treated with FOLFOXIRI plus Bev.

\section{Methods}

\section{Patients}

Patients diagnosed with $\mathrm{mCRC}$ and that received FOLFOXIRI plus Bev between December 2015 and December 2017 at the Cancer Institute Hospital, Tokyo, Japan were included in the study based on the following eligibility criteria: 1) histologically confirmed colorectal adenocarcinoma; 2) unresectable or recurrent disease; 3) no previous chemotherapy except for adjuvant chemotherapy completed more than 6 months prior to the starting date of FOLFOXIRI plus Bev treatment. The protocol summary was described on the hospital website, and the subjects were provided with the opportunity to opt-out. Therefore, no new consent for this study was required from the patients.

\section{Data collection}

All data were collected by reviewing medical records and imaging results. We confirmed the patient age, sex, and Eastern Cooperative Oncology Group Performance Status (ECOG-PS). Data regarding the primary tumor site, the histological type of primary site tumor, whether primary resection was performed, the metastatic sites, and the number of metastatic sites were also considered. Any previous adjuvant chemotherapy, the tumor maker level before chemotherapy, RAS and UGT1A1 status, the number of chemotherapy cycles, tumor response (objective response and early tumor shrinkage (ETS)), toxicity, conversion surgery rate, the date of disease progression, and the date of the last follow-up were also evaluated.

\section{Treatment and evaluation}

Bev was administered as a $5 \mathrm{mg} / \mathrm{kg}$ intravenous dose. FOLFOXIRI treatment consisted of a $165 \mathrm{mg} / \mathrm{m}^{2}$ intravenous infusion of irinotecan for $60 \mathrm{~min}$, followed by an $85 \mathrm{mg} / \mathrm{m}^{2}$ intravenous infusion of oxaliplatin given concurrently with $200 \mathrm{mg} / \mathrm{m}^{2}$ leucovorin for $120 \mathrm{~min}$ followed by a $3200 \mathrm{mg} /$ $\mathrm{m}^{2}$ continuous infusion of fluorouracil for $48 \mathrm{~h}$. The primary endpoint is the incidence of grade 3 or 4 neutropenia after administrating PEG-G-CSF. PEG-G-CSF (3.6 mg) starting at day four was administered every 2 weeks until progression. Whether PEG-G-CSF was used as a primary preventative treatment for neutropenia or as a secondary treatment after a patient experienced grade 4 neutropenia or FN was decided by the treating physician. In addition, the overall tumor response was assessed according to the Response Evaluation Criteria in Solid Tumors (RECIST) version 1.1 and toxicity was graded according to the Common Terminology Criteria for Adverse Events (CTCAE) version 4.0. PFS was measured as the day of initiation of FOLFOXIRI plus Bev therapy to the day on which disease progression was confirmed or to the final day of follow-up without disease progression. OS was measured as the day of initiation of FOLFOXIRI plus Bev therapy until the final day of follow-up. ETS was defined 
as the relative change in the sum of the longest diameters at week eight ( \pm 4 weeks) compared to that of the baseline (cutoff: $20 \%)$.

\section{Statistical analysis}

PFS and OS rates were estimated using the KaplanMeier method. All statistical analyses were performed using EZR software (Saitama Medical Center, Jichi Medical University, Saitama, Japan), which is a graphical user interface for R (The R Foundation for Statistical Computing, Vienna, Austria).

\section{Results}

\section{Patient characteristics}

The demographics and clinical characteristics of the 26 patients before the initiation of FOLFOXIRI plus Bev therapy are summarized in Table 1 . Out of the 26 patients, 20 (77.0\%) received PEG-G-CSF. Eleven patients received it secondarily to treat neutropenia. Among these 11 patients, 2 had previously been treated prophylactically with conventional G-CSF. Nine patients were administrated PEG-G-CSF prophylactically (Fig. 1). The median follow-up period was 24.2 months (range, 13.6NA). The median age of the patients was 53.5 years (range, 27-74 years). Thirteen patients $(50.0 \%)$ were male and 18 patients (69.2\%) had an ECOG-PS of 0. The primary location of colorectal cancer was on the right side for eight $(30.8 \%)$ of the patients. In addition, in the prophylactic PEG-G-CSF group, the right-sided primary tumor location was more frequent than those in the non-prophylactic PEG-G-CSF group (55.6\% vs. 9.0\% $P<$ $0.05)$. The histology type was either poorly differentiated or mucinous adenocarcinoma in 5 patients $(19.3 \%)$ and the primary lesion was resected in eight patients (30.8\%). Metastatic lesions of the liver, lung, lymph nodes and peritoneum were detected in 23 (88.4\%), 7 (26.9\%), 16 $(61.5 \%)$, and $5(19.3 \%)$ of the patients, respectively. Twenty-one patients (80.7\%) had two or more metastatic sites. The median carcinoembryonic antigen (CEA) and carbohydrate antigen (CA19-9) levels before chemotherapy were $88.0 \mathrm{ng} / \mathrm{ml}$ (range, 1.5-9205) and $75.4 \mathrm{IU} / \mathrm{ml}$ (range, $<2-50,000$ ), respectively. Twenty-three patients (88.5\%) had RAS mutation and UGT1A1 polymorphism was observed in eight patients (30.7\%).

Abbreviations: ECOG PS, eastern cooperative oncology group performance status; CEA, carcinoembryonic antigen; CA19-9, carbohydrate antigen 19-9; FN: febrile neutropenia; PEG-G-CSF: polyethylene glycolconjugated granulocyte colony stimulating factor

Adverse events, efficacy, and safety of PEG-GCSF in mCRC patients treated with FOLFOXIRI plus Bev

Grade3 or 4 toxicities of FOLFOXIRI plus Bev were shown in Table 2. The most common adverse event was hematological toxicity with grade 3 or 4 neutropenia, which was observed in 14 patients (53.8\%). Grade $3 \mathrm{FN}$ was observed in two patients (7.7\%). Other hematological or non-hematological toxicities were less frequent such as diarrhea being observed in two patients (7.7\%). No treatment-related deaths occurred. Of the 26 patients, 20 (77\%) received PEG-G-CSF. None of the patients developed grade 3 or 4 neutropenia after receiving PEG-G-CSF. Ten of the 26 patients (38.5\%) received a reduction in their dose of FOLFOXIRI plus Bev. Six of the 11 patients $(54.6 \%)$ who received PEG-G-CSF secondarily to treat neutropenia were able to continue treating with FOLFOXIRI plus Bev without the need for a dose adjustment. On the other hand, in the 9 patients given PEG-G-CSF prophylactically, 2 (22.2\%) required the dose adjustment due to non-hematological adverse events. There were no severe adverse events associated with PEG-G-CSF treatment.

\section{Treatment outcomes}

Treatment outcomes was shown in Table 3, respectively. The median number of treatment cycles per patient was 6.5 (range, 1.0-14.0). The ORR was $65.3 \%$ (95\% confidence interval $[\mathrm{CI}], 44.0-83.0)$ and the disease control rate was $84.5 \%$ (95\% CI, 65.0-96.0). PFS and OS were 9.6 months (95\% CI, 7.2-16.9) and 24.2 months $(95 \% \mathrm{CI}$, 13.6-NA), respectively (Fig. 2). Thirteen patients (50.0\%) were identified as demonstrating early tumor shrinkage, and seven patients $(26.9 \%)$ received conversion surgery. As for the outcome of the patients using PEG-G-CSF, the PFSs were 4.9 and 16.9 months for the prophylactic and secondary groups, respectively $(p<0.05)$.

\section{Discussion}

In the current study, we evaluated the efficacy and safety of the PEG-G-CSF for preventing neutropenia in mCRC patients treated with FOLFOXIRI plus Bev. PEG-G-CSF prevented the development of severe neutropenia without any increases of adverse events. FN is one of the lifethreatening adverse events of chemotherapy. In the 1990s, G-CSF was widely used in the clinic as a leading supportive therapy for FN. There is substantial data regarding the effectiveness of G-CSF for cancer chemotherapy $[14,15]$. Compared to conventional G-CSF, the number of visits to a hospital by patients and the workload of the medical staff both decreased when we used PEG-G-CSF. This demonstrates a great benefit for the outpatient clinic.

There are several reports regarding the efficacy of PEG-G-CSF for neutropenia and FN in both mCRC and other cancers, as shown in Table 4. A Japanese doubleblind placebo-controlled randomized phase 3 trial of PEG-G-CSF in 343 breast cancer patients receiving docetaxel and cyclophosphamide chemotherapy showed 
Table 1 Patient demographics and clinical characteristics

\begin{tabular}{|c|c|c|c|c|}
\hline Characteristics & $\begin{array}{l}\text { Total }(\boldsymbol{n}=26) \text { No. of patients } \\
(\%)\end{array}$ & $\begin{array}{l}\text { With Prophylactic PEG-G-CSF } \\
(\boldsymbol{n}=9)\end{array}$ & $\begin{array}{l}\text { Without Prophylactic PEG-G-CSF }(\boldsymbol{n}= \\
\text { 11) }\end{array}$ & $\begin{array}{l}\text { No use of PEG-G-CSF } \\
(\boldsymbol{n}=6)\end{array}$ \\
\hline \multicolumn{5}{|c|}{ Age at enrollment, years } \\
\hline Median & 53.5 & 51 & 58 & 40.5 \\
\hline Range & $27-74$ & $34-74$ & $27-67$ & $35-57$ \\
\hline \multicolumn{5}{|l|}{ Gender } \\
\hline Male & $13(50.0)$ & $6(66.7)$ & $3(27.2)$ & $4(66.7)$ \\
\hline Female & $13(50.0)$ & $3(33.3)$ & $8(72.3)$ & $2(33.3)$ \\
\hline \multicolumn{5}{|l|}{ ECOG-PS } \\
\hline 10 & $18(69.2)$ & $8(88.9)$ & $7(63.6)$ & $3(50.0)$ \\
\hline$/ 1$ & $8(30.8)$ & $1(11.1)$ & $4(36.4)$ & $3(50.0)$ \\
\hline \multicolumn{5}{|l|}{ Primary location } \\
\hline Right & $8(30.8)$ & $5(55.6)$ & $1(9.0)$ & $2(33.3)$ \\
\hline Left & $18(69.2)$ & $4(44.4)$ & $10(91.0)$ & $4(66.7)$ \\
\hline \multicolumn{5}{|l|}{ Histology } \\
\hline Diffuse & $5(19.3)$ & $1(11.1)$ & $3(27.2)$ & $1(16.7)$ \\
\hline Intestinal & $21(80.7)$ & $8(88.9)$ & $8(72.3)$ & $5(83.3)$ \\
\hline \multicolumn{5}{|c|}{ Primary resection before chemotherapy } \\
\hline Yes & $8(30.8)$ & $3(33.3)$ & $4(36.4)$ & $1(16.7)$ \\
\hline No & $18(69.2)$ & $6(66.7)$ & $7(63.6)$ & $5(83.3)$ \\
\hline \multicolumn{5}{|l|}{ Diagnosis of metastasis } \\
\hline Metachronous & $5(19.3)$ & $3(33.3)$ & $2(18.2)$ & $0(0)$ \\
\hline Synchronous & $21(80.7)$ & $6(66.7)$ & $9(81.8)$ & $6(100)$ \\
\hline \multicolumn{5}{|l|}{ Metastatic site } \\
\hline Liver & $23(88.4)$ & $8(88.9)$ & $9(81.8)$ & $6(100)$ \\
\hline Lung & $7(26.9)$ & $3(33.3)$ & $4(36.4)$ & $0(0)$ \\
\hline Lymph node & $16(61.5)$ & $2(22.2)$ & $8(72.3)$ & $6(100)$ \\
\hline Peritoneum & $5(19.3)$ & $0(0)$ & $4(36.4)$ & $1(16.7)$ \\
\hline Other & $3(11.5)$ & $2(22.2)$ & $1(9.0)$ & $0(0)$ \\
\hline \multicolumn{5}{|c|}{ Number of metastatic sites } \\
\hline 1 & $4(15.4)$ & $2(22.2)$ & $2(18.2)$ & $0(0)$ \\
\hline$\geq 2$ & $22(84.6)$ & $7(77.8)$ & $9(81.8)$ & $6(100)$ \\
\hline \multicolumn{5}{|c|}{ Previous adjuvant chemotherapy } \\
\hline Yes & $2(7.7)$ & $1(11.1)$ & $1(9.0)$ & $0(0)$ \\
\hline No & $24(92.3)$ & $8(88.9)$ & $10(91.0)$ & $6(100)$ \\
\hline \multicolumn{5}{|l|}{ RAS status } \\
\hline Wild type & $3(11.5)$ & $0(0)$ & $2(18.2)$ & $1(16.7)$ \\
\hline Mutant type & $23(88.5)$ & $9(100)$ & $9(81.8)$ & $5(83.3)$ \\
\hline \multicolumn{5}{|l|}{ UGT1A1 Status } \\
\hline Wild type & $7(26.9)$ & $3(33.3)$ & $3(27.2)$ & $1(16.7)$ \\
\hline *6 & $6(23.0)$ & $2(22.2)$ & $2(18.2)$ & $2(33.3)$ \\
\hline *28 & $2(7.7)$ & $0(0)$ & $2(18.2)$ & $0(0)$ \\
\hline Unknown & $11(42.4)$ & $4(44.5)$ & $4(36.4)$ & $3(50.0)$ \\
\hline CEA median, [range] & $88.0[1.5-9205]$ & $12.2[4.6-5638]$ & $155.9[5-25,873]$ & $155.9[5-25,873]$ \\
\hline $\begin{array}{l}\text { CA19-9 median, } \\
\text { [range] }\end{array}$ & $75.4[2-50,000]$ & $99.7[5.9-50,000]$ & $40.2[2.7-982]$ & $40.2[2.7-982]$ \\
\hline
\end{tabular}


The frequency of using PEG-G-CSF $n=26$

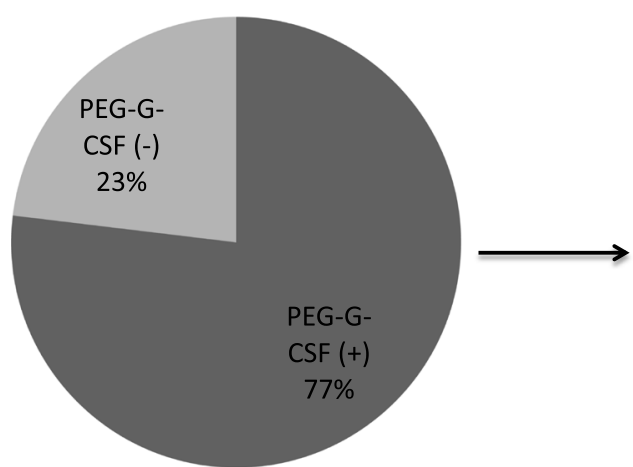

Reasons $\mathrm{n}=\mathbf{2 0}$

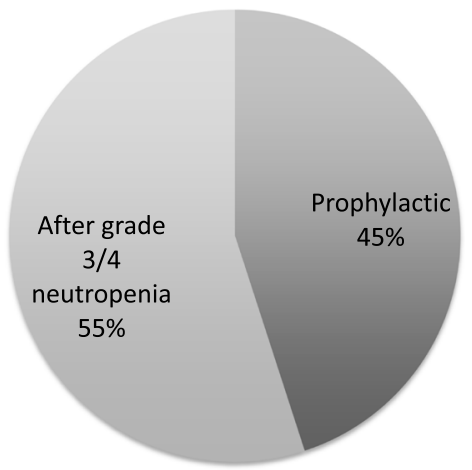

Fig. 1 Frequency and reasons for the use of polyethylene glycol-conjugated granulocyte colony-stimulating factor (PEG-G-CSF)

that the incidence of FN was significantly lower in the PEG-G-CSF group compared to that in the placebo group $(1.2 \%$ vs. $68.8 \%, P<0.001)$ [24]. Regarding mCRC patients, in a phase 3 double-blind trial that evaluated the efficacy of PEG-G-CSF compared to a placebo in reducing the incidence of grade 3 or 4 FN in patients with advanced CRC receiving Bev combined with first-line chemotherapy, PEG-G-CSF significantly reduced the incidence of grade 3 or $4 \mathrm{FN}$ in the first four treatment cycles (PEG-G-CSF 2.4\%, placebo, 5.7\%, $P=0.014$ ) [18]. Another randomized placebo-controlled phase 2 study examined PEG-G-CSF efficacy and safety in patients with CRC that received chemotherapy every 2 weeks. Results from this study showed that PEG-G-CSF significantly reduces the incidence of grade 3 or 4 FN (PEGG-CSF, 2.0\%; placebo, 8.0\%; $P<0.001$ ) [28]. Notably, this study demonstrated that PEG-G-CSF could prevent

Table 2 Toxicities according to CTCAE, version 4.0 (grade 3 or higher)

\begin{tabular}{ll}
\hline Characteristics & $\begin{array}{l}\text { Total }(\boldsymbol{n}=26) \\
\text { No. of patients (\%) }\end{array}$ \\
\hline Hematotoxicity & $14(53.8)$ \\
Neutropenia & $2(7.7)$ \\
Febrile neutropenia & $1(3.8)$ \\
Anemia & \\
Nonhematotoxicity & $2(7.7)$ \\
Infection & $1(3.8)$ \\
Nausea & $1(3.8)$ \\
Fatigue & $2(7.7)$ \\
Diarrhea & $1(3.8)$ \\
Spinal infarction & $1(3.8)$ \\
Renal dysfunction & $1(3.8)$ \\
Hypertension & $2(7.7)$ \\
Perforation &
\end{tabular}

severe neutropenia in patients receiving FOLFOXIRI plus Bev on a two-week cycle without an increase of adverse events, consistent with previous reports. However, the safety of PEG-G-CSF had not been established when administered within 14 days before the start of chemotherapy. It is recommended that the administration interval of PEG-G-CSF should be 2 weeks or longer.

In addition, UGT1A1 polymorphism was detected in this study in eight (30.7\%) of the patients (*6 in six patients, ${ }^{*} 28$ in two patients). Among these patients with UGT1A1 polymorphism, six had been administered PEG-G-CSF, two after the development of grade 3 neutropenia, and four prophylactically. In Japan, the incidence of $U G T 1 A 1 * 6$ polymorphism is higher than that in the US and European countries [41-43]. In a Japanese phase 2 trial of FOLFOXIRI plus Bev in mCRC patients, the frequency of neutropenia in patients with UGT1A1 *6 or *28 polymorphism is higher than that in patients with wild-type UGT1A1 ${ }^{10}$. However, in the current study, no patients experienced severe neutropenia after the administration of PEG-G-CSF, even those with UGT1A1" 6 or " 28 polymorphism. Furthermore, 5 of the 6 patients could continue the FOLFOXIRI plus Bev treatment without any need for a dose adjustment. These data suggest that the administration of PEG-GCSF with a two-week cycle may be safe and PEG-G-CSF can prevent severe neutropenia in patients with UGT1A1 *6 or *28 polymorphism.

There were several limitations of our study. Firstly, this was a retrospective study with relatively small sample size. Secondly, PFS was significantly different between the prophylactic and non-prophylactic PEG-GCSF groups. This difference was partially because the mCRC patients in the prophylactic PEG-G-CSF group mostly had the tumor on the right side, rather than the left, and this sub-group has poorer survival than the patients with the tumor on the left. Therefore, further 
Table 3 Chemotherapeutic Efficacy

\begin{tabular}{|c|c|c|c|c|}
\hline Characteristics & $\begin{array}{l}\text { Total }(\boldsymbol{n}=26) \text { No. of patients } \\
(\%)\end{array}$ & $\begin{array}{l}\text { With Prophylactic PEG-G-CSF } \\
(\boldsymbol{n}=9)\end{array}$ & $\begin{array}{l}\text { Without Prophylactic PEG-G-CSF } \\
(\boldsymbol{n}=11)\end{array}$ & $\begin{array}{l}\text { No use of PEG-G-CSF } \\
(\boldsymbol{n}=6)\end{array}$ \\
\hline \multicolumn{5}{|l|}{ Number of cycles } \\
\hline Median & 6.5 & 8 & 6 & 7 \\
\hline Range & $1.0-14.0$ & $3.0-10.0$ & $5.0-14.0$ & $1.0-11.0$ \\
\hline \multicolumn{5}{|l|}{ Dose reduction } \\
\hline Yes & $10(38.5)$ & $2(22.2)$ & $5(45.4)$ & $3(50.0)$ \\
\hline No & $16(61.5)$ & $7(77.8)$ & $6(54.6)$ & $3(50.0)$ \\
\hline \multicolumn{5}{|l|}{ ORR } \\
\hline Partial response & $17(65.3)$ & $3(33.3)$ & $10(90.9)$ & $4(66.7)$ \\
\hline Stable disease & $5(19.2)$ & $2(22.3)$ & $1(9.1)$ & $2(33.3)$ \\
\hline $\begin{array}{l}\text { Progressive } \\
\text { disease }\end{array}$ & $1(3.8)$ & $1(11.1)$ & $0(0)$ & $0(0)$ \\
\hline Not evaluate & $3(11.5)$ & $3(33.3)$ & $0(0)$ & $0(0)$ \\
\hline \multicolumn{5}{|c|}{ Conversion surgery } \\
\hline Yes & $7(26.9)$ & $2(22.2)$ & $5(45.4)$ & $2(33.3)$ \\
\hline No & $19(73.1)$ & $7(77.8)$ & $6(54.6)$ & $4(66.7)$ \\
\hline \multicolumn{5}{|c|}{ Early Tumor Response } \\
\hline Yes & $13(50.0)$ & $1(11.1)$ & $9(81.8)$ & $3(50.0)$ \\
\hline No & $10(38.4)$ & $5(55.6)$ & $2(18.2)$ & $3(50.0)$ \\
\hline Not evaluated & $3(11.6)$ & $3(33.3)$ & $0(0)$ & $0(0)$ \\
\hline
\end{tabular}

research is necessary to evaluate the correlation between the timing of PEG-G-CSF use (prophylactic or nonprophylactic) and survival. However, even with these limitations, the results of this study showed that neutropenia, which is the most common adverse event in patients under treatment with FOLFOXIRI plus Bev, could be prevented by using PEG-G-CSF.

Abbreviations: $\mathrm{PC}$, pancreatic cancer; $\mathrm{BC}$, breast cancer; CRC, colorectal cancer; $\mathrm{ML}$, malignant lymphoma; DLBCL, diffuse large B-cell lymphoma; NSCLC, non- small cell lung carcinoma; NHL, non-Hodgkin's lymphoma; HNC, head and neck carcinoma; AML, acute myeloid leukemia; mFOLFIRINOX, modified fluorouracil, leucovorin, oxaliplatin, and irinotecan: EC, epirubicin and cyclophosphamide; TC, Taxotere and cyclophosphamide; ET, endocrine therapy; CHASE(R), cyclophosphamide, cytarabine, dexamethasone, etoposide (and rituximab); DA,; TAC, taxotate, adriamycin and cyclophosphamide, (R) CHOP, rituximab, cyclophosphamide, doxorubicin, vincristine and prednisolone; PC, paclitaxel
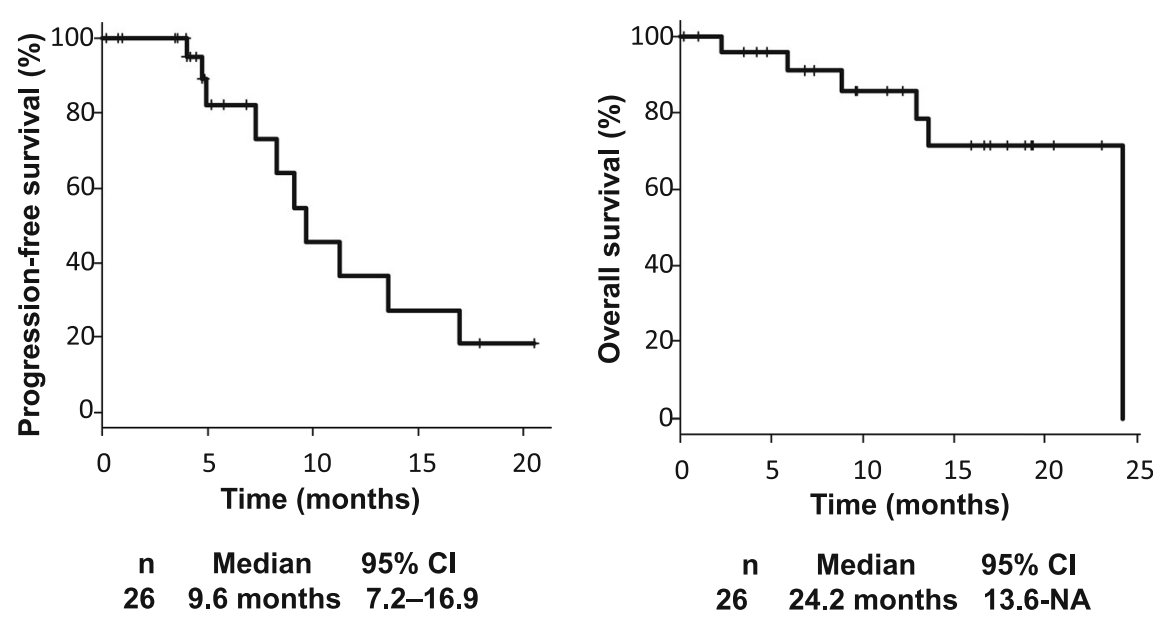

Fig. 2 Progression-free survival and overall survival rates of the study cohort 
Table 4 Previous reports of efficacy of PEG-G-CSF

\begin{tabular}{|c|c|c|c|c|c|c|}
\hline No. & Author & Year & $\begin{array}{l}\text { Primary } \\
\text { Tumor }\end{array}$ & Regimen & $\begin{array}{l}\text { Patients } \\
\text { number }\end{array}$ & Major outcomes \\
\hline 1 & $\begin{array}{l}\text { Yamao et al. } \\
{[16]}\end{array}$ & 2019 & PC & mFOLFIRINOX & 45 & PFS (prolonged) \\
\hline 2 & Xie et al. [17] & 2018 & $\mathrm{BC}$ & $\mathrm{EC}, \mathrm{TC}, \mathrm{ET}$ & 569 & $\begin{array}{l}\text { Incidence and duration of } \\
\text { grade } 3 / 4 \text { neutropenia }\end{array}$ \\
\hline 3 & $\begin{array}{l}\text { Pinter et al. } \\
\text { [18] }\end{array}$ & 2017 & CRC & FOLFOX, FOLFIRI & 845 & $\begin{array}{l}\text { Incidence of grade } 3 / 4 \mathrm{FN} \text { in } \\
\text { the first } 4 \text { cycles }\end{array}$ \\
\hline 4 & $\begin{array}{l}\text { Kubo et al. } \\
\text { [19] }\end{array}$ & 2016 & $M L$ & CHASE(R) & 111 & $\begin{array}{l}\text { Duration of severe } \\
\text { neutropenia }\end{array}$ \\
\hline 5 & Lee et al. [20] & 2016 & $B C$ & TAC & 60 & $\begin{array}{l}\text { Duration of grade } 4 \\
\text { neutropenia in cycle } 1\end{array}$ \\
\hline 6 & $\begin{array}{l}\text { Blackwell } \\
\text { et al. [21] }\end{array}$ & 2016 & $B C$ & TAC & 308 & $\begin{array}{l}\text { Duration of severe } \\
\text { neutropenia during cycle } 1\end{array}$ \\
\hline 7 & $\begin{array}{l}\text { Harbeck et al. } \\
\text { [22] }\end{array}$ & 2016 & $\mathrm{BC}$ & TAC & 316 & $\begin{array}{l}\text { Duration of severe } \\
\text { neutropenia during cycle } 1\end{array}$ \\
\hline 8 & $\begin{array}{l}\text { Zhang et al. } \\
{[23]}\end{array}$ & 2015 & $B C$ & TAC & 171 & $\begin{array}{l}\text { Incidence of grade 3/4 } \\
\text { neutropenia }\end{array}$ \\
\hline 9 & $\begin{array}{l}\text { Kosaka et al. } \\
{[24]}\end{array}$ & 2015 & $\mathrm{BC}$ & TC & 351 & Incidence of FN \\
\hline 10 & $\begin{array}{l}\text { Bozzoli et al. } \\
{[25]}\end{array}$ & 2015 & DLBCL & $\mathrm{RCHOP}$ & 51 & $\begin{array}{l}\text { Frequency of FN and } \\
\text { unplanned hospitalizations }\end{array}$ \\
\hline 11 & $\begin{array}{l}\text { Gladkov et al. } \\
\text { [26] }\end{array}$ & 2015 & $\mathrm{BC}$ & Doxorubicin/Docetaxel & 78 & Incidence of adverse events \\
\hline 12 & Shi et al. [27] & 2013 & $\begin{array}{l}\text { BC, NSCLC, } \\
\text { NHL, HNC }\end{array}$ & $\mathrm{PC}, \mathrm{AC}, \mathrm{CHOP}$ & 337 & $\begin{array}{l}\text { Rate of protection against } \\
\text { grade } 4 \text { neutropenia }\end{array}$ \\
\hline 13 & $\begin{array}{l}\text { Hecht et al. } \\
\text { [28] }\end{array}$ & 2010 & CRC & FOLFOX, FOLFIRI, FOIL & 241 & $\begin{array}{l}\text { Incidence of grade } 3 / 4 \\
\text { neutropenia. }\end{array}$ \\
\hline 14 & Fox et al. [29] & 2009 & Sarcoma & VDC, IE & 34 & $\begin{array}{l}\text { Duration of severe } \\
\text { neutropenia }\end{array}$ \\
\hline 15 & $\begin{array}{l}\text { Sierra et al. } \\
{[30]}\end{array}$ & 2008 & AML & Idarubicin/cytarabine & 84 & Assisting neutrophil recovery \\
\hline 16 & $\begin{array}{l}\text { von } \\
\text { Minckwitz } \\
\text { et al. [31] }\end{array}$ & 2008 & $B C$ & TAC & 1256 & $\begin{array}{l}\text { Primary prophylaxis of FN } \\
\text { and related toxic effects }\end{array}$ \\
\hline 17 & $\begin{array}{l}\text { Bladucci et al. } \\
\text { [32] }\end{array}$ & 2007 & $\begin{array}{l}\text { Solid } \\
\text { tumors or } \\
\mathrm{NHL}\end{array}$ & $\begin{array}{l}\text { Carboplatin, Cisplatin, Doxorubicin, Doxorubicin and Paclitaxel, } \\
\text { AC, Docetaxel, ACT, FEC, CHOP, EPOCH, Topotecan }\end{array}$ & 852 & $\begin{array}{l}\text { Proportion of patients } \\
\text { experiencing FN }\end{array}$ \\
\hline 18 & $\begin{array}{l}\text { Romieu et al. } \\
\text { [33] }\end{array}$ & 2007 & $B C$ & FEC & 60 & $\begin{array}{l}\text { Incidence of neutropenic } \\
\text { events }\end{array}$ \\
\hline 19 & $\begin{array}{l}\text { Vogel et al. } \\
{[34]}\end{array}$ & 2005 & $\mathrm{BC}$ & Docetaxel & 928 & $\begin{array}{l}\text { Percentage of patients } \\
\text { developing FN }\end{array}$ \\
\hline 20 & $\begin{array}{l}\text { Grigg et al. } \\
{[35]}\end{array}$ & 2003 & $\mathrm{NHL}$ & $\mathrm{CHOP}$ & 50 & $\begin{array}{l}\text { Duration of grade } 4 \\
\text { neutropenia }\end{array}$ \\
\hline 21 & $\begin{array}{l}\text { Vose et al. } \\
{[36]}\end{array}$ & 2003 & $M L$ & ESHAP & 66 & Incidence of grade 4 FN \\
\hline 22 & $\begin{array}{l}\text { Green et al. } \\
\text { [37] }\end{array}$ & 2003 & $\mathrm{BC}$ & DA & 157 & $\begin{array}{l}\text { Incidence of Grade } 4 \\
\text { neutropenia }\end{array}$ \\
\hline 23 & $\begin{array}{l}\text { Holmes et al. } \\
\text { [38] }\end{array}$ & 2002 & $B C$ & DA & 310 & Absolute neutrophil count \\
\hline 24 & $\begin{array}{l}\text { Holmes et al. } \\
\text { [39] }\end{array}$ & 2002 & $\mathrm{BC}$ & DA & 154 & $\begin{array}{l}\text { Incidence of Grade } 4 \\
\text { neutropenia in cycle } 1\end{array}$ \\
\hline 25 & $\begin{array}{l}\text { Johnston } \\
\text { et al. [40] }\end{array}$ & 2000 & NSCLC & Carboplatin and Paclitaxel & 13 & Serum concentrations \\
\hline
\end{tabular}


and carboplatin; AC, adriamycin and cyclophosphamide; VDC, vincristine, doxorubicin and cyclophosphamide; IE, fosfamide and etoposide; ACT, doxorubicin, cyclophosphamide and docetaxel; FEC, falmorubicin, endoxane and 5-fluorouracil; EPOCH, etoposide, prednisolone, vincristine, cyclophosphamide and doxorubicin; ESHAP, prednisolone, etoposide, cytarabine and cisplatin; DA, docetaxel and doxorubicin;

\section{Conclusion}

PEG-G-CSF is useful for both primary and secondary prevention of severe neutropenia in mCRC patients treated with FOLFOXIRI plus Bev without increases in adverse events.

\begin{abstract}
Abbreviations
PEG-G-CSF: Polyethylene glycol conjugated granulocyte colony-stimulating factor; mCRC: Metastatic colorectal cancer; FOLFOXIRI: Fluorouracil, leucovorin, oxaliplatin, and irinotecan; Bev: Bevacizumab; ORR: Overall response rate; PFS: Progression-free survival; OS: Overall survival; ESMO: European Society for Medical Oncology; FN: Febrile neutropenia; ECOG-PS: Eastern Cooperative Oncology Group Performance Status; ETS: Early tumor shrinkage; RECIST: Response Evaluation Criteria in Solid Tumors; CTCAE: Common Terminology Criteria for Adverse Events; CEA: Carcinoembryonic antigen; CA19-9: Carbohydrate antigen; PC: Pancreatic cancer; BC: Breast cancer; CRC: Colorectal cancer; ML: Malignant lymphoma; DLBCL: Diffuse large B-cell lymphoma; NSCLC: Non-small cell lung carcinoma; NHL: Non-Hodgkin's lymphoma; HNC: Head and neck carcinoma; AML: Acute myeloid leukemia; mFOLFIRINOX: Modified fluorouracil, leucovorin, oxaliplatin, and irinotecan; EC: Epirubicin and cyclophosphamide; TC: Taxotere and cyclophosphamide; ET: Endocrine therapy; CHASE(R): Cyclophosphamide, cytarabine, dexamethasone, etoposide (and rituximab); DA: Docetaxel and doxorubicin; TAC: Taxotate, adriamycin and cyclophosphamide; (R)CHOP: (Rituximab), cyclophosphamide, doxorubicin, vincristine, and prednisolone; PC: Paclitaxel and carboplatin; AC: Adriamycin and cyclophosphamide; VDC: Vincristine, doxorubicin, and cyclophosphamide; IE: Fosfamide and etoposide; ACT: Doxorubicin, cyclophosphamide, and docetaxel; FEC: Falmorubicin, endoxane and 5-fluorouracil; EPOCH: Etoposide, prednisolone, vincristine, cyclophosphamide, and doxorubicin; ESHAP: Prednisolone, etoposide, cytarabine and cisplatin
\end{abstract}

\section{Acknowledgments}

We would like to express special thanks to Yuki Horiike for her data management.

\section{Authors' contributions}

$Y K, H O$, and ES analyzed the clinical data and wrote the original manuscript. $Y K, H O, E S, Y O, I N, T S, T W, M O, A O, D T, M S, K C$ and $K Y$ were all involved in the administration of chemotherapy. All authors contributed to editing the manuscript and approved the final version.

\section{Funding}

The author reports that no funding was received for this analysis.

\section{Availability of data and materials}

All data generated or analyzed during this study are included in this published article.

\section{Ethics approval and consent to participate}

The study was performed in accordance with the Declaration of Helsinki and was approved by the Cancer Institute Hospital Institutional Review Board (Registry no: 2018-1014). The protocol summary was described on the hospital website, and the subjects were provided with the opportunity to opt-out. Therefore, no new consent for this study was required from the patients.
Consent for publication

Not applicable.

\section{Competing interests}

The author reports no conflicts of interest in this work.

Received: 3 September 2019 Accepted: 14 April 2020

Published online: 28 April 2020

\section{References}

1. Grothey A, Sargent D, Goldberg RM, et al. Survival of patients with advanced colorectal cancer improves with the availability of fluorouracilleucovorin, irinotecan, and oxaliplatin in the course of treatment. J Clin Oncol. 2004;22:1209-14.

2. Falcone A, Ricci S, Brunetti I, et al. Phase III trial of infusional fluorouracil, leucovorin, oxaliplatin, and irinotecan (FOLFOXIRI) compared with infusional fluorouracil, leucovorin, and irinotecan (FOLFIRI) as first-line treatment for metastatic colorectal cancer: the Gruppo Oncologico Nord Ovest. J Clin Oncol. 2007:25:1670-6.

3. Loupakis F, Cremolini C, Masi G, et al. Initial therapy with FOLFOXIRI and bevacizumab for metastatic colorectal cancer. New Engl J Med. 2014;371:1609-8.

4. Cremolini C, Loupakis F, Masi G, et al. FOLFOXIRI or FOLFOXIRI plus bevacizumab as first-line treatment of metastatic colorectal cancer: a propensity score-adjusted analysis from two randomized clinical trials. Ann Oncol. 2016:27:843-9.

5. Yoshino T, Arnold D, Taniguchi $\mathrm{H}$, et al. Pan-Asian adapted ESMO consensus guidelines for the management of patients with metastatic colorectal cancer: a JSMO-ESMO initiative endorsed by CSCO, KACO, MOS, SSO and TOS. Ann Oncol. 2018;29:44-70.

6. Watanabe T, Muro K, Ajioka Y, et al. Japanese Society for Cancer of the Colon and Rectum (JSCCR) guidelines 2016 for the treatment of colorectal cancer. Int J Clin Oncol. 2018:23:1-34.

7. Taniguchi $\mathrm{H}$, Okamoto W, Muro K, et al. Clinical validation of newly developed multiplex kit using Luminex XMAP technology for detecting simultaneous RAS and BRAF mutations in colorectal cancer: results of the RASKET-B Study. Neoplasia (New York, NY). 2018:20:1219-26.

8. Vamvakas L, Athanasiadis A, Karampeazis A, et al. Clinical outcome of elderly patients with metastatic colorectal cancer treated with FOLFOXIRI versus FOLFIRI: subgroup analysis of a randomized phase III trial from the Hellenic oncology research group (HORG). Crit Rev Oncol/Hematol. 2010;76:61-7.

9. Masi G, Loupakis F, Salvatore $L$, et al. Bevacizumab with FOLFOXIRI (irinotecan, oxaliplatin, fluorouracil, and folinate) as first-line treatment for metastatic colorectal cancer: a phase 2 trial. Lancet Oncol. 2010;11:845-52

10. Xu W, Kuang M, Gong Y, et al. Survival benefit and safety of the combinations of FOLFOXIRI +/- bevacizumab versus the combinations of FOLFIRI +/- bevacizumab as first-line treatment for unresectable metastatic colorectal cancer: a meta-analysis. Onco Targets Ther. 2016;9:4833-42.

11. Marques RP, Duarte GS, Sterrantino C, et al. Triplet (FOLFOXIRI) versus doublet (FOLFOX or FOLFIRI) backbone chemotherapy as first-line treatment of metastatic colorectal cancer: a systematic review and meta-analysis. Crit Rev Oncol/Hematol. 2017;118:54-62.

12. Oki E, Kato T, Bando H, Yoshino $T$, et al. A multicenter clinical phase II study of FOLFOXIRI plus Bevacizumab as first-line therapy in patients with metastatic colorectal cancer: QUATTRO study. Clin Colorectal Cancer. 2018; 17:147-55.

13. Smith TJ, Khatcheressian J, Lyman GH, et al. 2006 update of recommendations for the use of white blood cell growth factors: an evidence-based clinical practice guideline. J Clin Oncol. 2006:24:3187-205.

14. Bohlius J, Herbst C, Reiser M, et al. Granulopoiesis-stimulating factors to prevent adverse effects in the treatment of malignant lymphoma. Cochrane Database Syst Rev. 2008;(4):CD003189.

15. Renner P, Milazzo S, Liu JP, et al. Primary prophylactic colony-stimulating factors for the prevention of chemotherapy-induced febrile neutropenia in breast cancer patients. Cochrane Database Syst Rev. 2012;(10):CD007913.

16. Yamao K, Takenaka M, Yoshikawa T, et al. Clinical safety and efficacy of secondary prophylactic Pegylated G-CSF in advanced pancreatic Cancer patients treated with mFOLFIRINOX: a single-center retrospective study. Intern Med. 2019;14:1993-2002.

17. Xie J, Cao J, Wang JF, et al. Advantages with prophylactic PEG-rhG-CSF versus rhG-CSF in breast cancer patients receiving multiple cycles of 
myelosuppressive chemotherapy: an open-label, randomized, multicenter phase III study. Breast Cancer Res Treat. 2018;168:389-99.

18. Pinter T, Klippel Z, Cesas A, et al. A phase III, randomized, double-blind, placebo-controlled trial of pegfilgrastim in patients receiving first-line FOLFOX/Bevacizumab or FOLFIRI/Bevacizumab for locally advanced or metastatic colorectal cancer: final results of the Pegfilgrastim and Anti-VEGF Evaluation Study (PAVES). Clin Colorectal Cancer. 2017;16:103-14.e103.

19. Kubo K, Miyazaki Y, Murayama T, et al. A randomized, double-blind trial of pegfilgrastim versus filgrastim for the management of neutropenia during $\mathrm{CHASE}(\mathrm{R})$ chemotherapy for malignant lymphoma. Br J Haematol. 2016;174:563-70.

20. Lee KH, Kim JY, Lee MH, et al. A randomized, multicenter, phase II/III study to determine the optimal dose and to evaluate the efficacy and safety of pegteograstim (GCPGC) on chemotherapy-induced neutropenia compared to pegfilgrastim in breast cancer patients: KCSG PC10-09. Support Care Cancer. 2016;24:1709-17.

21. Blackwell K, Semiglazov V, Krasnozhon D, et al. Comparison of EP2006, a filgrastim biosimilar, to the reference: a phase III, randomized, double-blind clinical study in the prevention of severe neutropenia in patients with breast cancer receiving myelosuppressive chemotherapy. Ann Oncol. 2015; 26:1948-53.

22. Harbeck N, Lipatov O, Frolova M, et al. Randomized, double-blind study comparing proposed biosimilar LA-EP2006 with reference pegfilgrastim in breast cancer. Future Oncol. 2016;12:1359-67.

23. Zhang W, Jiang Z, Wang L, Li C, Xia J. An open-label, randomized, multicenter dose-finding study of once-per-cycle pegfilgrastim versus daily filgrastim in Chinese breast cancer patients receiving TAC chemotherapy. Med Oncol. 2015;32:147.

24. Kosaka Y, Rai Y, Masuda N, et al. Phase III placebo-controlled, double-blind, randomized trial of pegfilgrastim to reduce the risk of febrile neutropenia in breast cancer patients receiving docetaxel/cyclophosphamide chemotherapy. Support Care Cancer. 2015;23:1137-43.

25. Bozzoli V, Tisi MC, Maiolo E, et al. Four doses of unpegylated versus one dose of pegylated filgrastim as supportive therapy in R-CHOP-14 for elderly patients with diffuse large B-cell lymphoma. Br J Haematol. 2015;169:787-94.

26. Gladkov O, Moiseyenko V, Bondarenko IN, et al. Phase II dose-finding study of balugrastim in breast cancer patients receiving myelosuppressive chemotherapy. Med Oncol. 2015;32:623.

27. Shi YK, Chen Q, Zhu YZ, et al. Pegylated filgrastim is comparable with filgrastim as support for commonly used chemotherapy regimens: a multicenter, randomized, crossover phase 3 study. Anti-Cancer Drugs. 2013;24:641-7.

28. Hecht JR, Pillai M, Gollard R, et al. A randomized, placebo-controlled phase ii study evaluating the reduction of neutropenia and febrile neutropenia in patients with colorectal cancer receiving pegfilgrastim with every-2-week chemotherapy. Clin Colorectal Cancer. 2010;9:95-101.

29. Fox E, Widemann BC, Hawkins DS, et al. Randomized trial and pharmacokinetic study of pegfilgrastim versus filgrastim after dose-intensive chemotherapy in young adults and children with sarcomas. Clin Cancer Res. 2009;15:7361-7.

30. Sierra J, Szer J, Kassis J, et al. A single dose of pegfilgrastim compared with daily filgrastim for supporting neutrophil recovery in patients treated for low-to-intermediate risk acute myeloid leukemia: results from a randomized, double-blind, phase 2 trial. BMC Cancer. 2008:8:195.

31. von Minckwitz G, Kümmel S, du Bois A, et al. Pegfilgrastim +/- ciprofloxacin for primary prophylaxis with TAC (docetaxel/doxorubicin/ cyclophosphamide) chemotherapy for breast cancer. Results from the GEPARTRIO study. Ann Oncol. 2008;19:292-8.

32. Balducci L, Al-Halawani H, Charu V, et al. Elderly cancer patients receiving chemotherapy benefit from first-cycle pegfilgrastim. Oncologist. 2007;12:1416-24.

33. Romieu G, Clemens M, Mahlberg R, et al. Pegfilgrastim supports delivery of FEC-100 chemotherapy in elderly patients with high risk breast cancer: a randomized phase 2 trial. Crit Rev Oncol Hematol. 2007;64:64-72.

34. Vogel CL, Wojtukiewicz MZ, Carroll RR, et al. First and subsequent cycle use of pegfilgrastim prevents febrile neutropenia in patients with breast cancer: a multicenter, double-blind, placebo-controlled phase III study. J Clin Oncol. 2005;23:1178-84.

35. Grigg A, Solal-Celigny P, Hoskin P, et al. Open-label, randomized study of pegfilgrastim vs. daily filgrastim as an adjunct to chemotherapy in elderly patients with non-Hodgkin's lymphoma. Leuk Lymphoma. 2003;44:1503-8.

36. Vose JM, Crump M, Lazarus H, et al. Randomized, multicenter, open-label study of pegfilgrastim compared with daily filgrastim after chemotherapy for lymphoma. J Clin Oncol. 2003;21:514-9.
37. Green MD, Koelbl H, Baselga J, et al. A randomized double-blind multicenter phase III study of fixed-dose single-administration pegfilgrastim versus daily filgrastim in patients receiving myelosuppressive chemotherapy. Ann Oncol. 2003:14:29-35.

38. Holmes FA, O'Shaughnessy JA, Vukelja S, et al. Blinded, randomized, multicenter study to evaluate single administration pegfilgrastim once per cycle versus daily filgrastim as an adjunct to chemotherapy in patients with high-risk stage II or stage III/IV breast cancer. J Clin Oncol. 2002;20:727-31.

39. Holmes FA, Jones SE, O'Shaughnessy J, et al. Comparable efficacy and safety profiles of once-per-cycle pegfilgrastim and daily injection filgrastim in chemotherapy-induced neutropenia: a multicenter dose-finding study in women with breast cancer. Ann Oncol. 2002;13:903-9.

40. Johnston E, Crawford J, Blackwell S, et al. Randomized, dose-escalation study of SD/01 compared with daily filgrastim in patients receiving chemotherapy. J Clin Oncol. 2000;18:2522-8.

41. Sai K, Saeki M, Saito Y, et al. UGT1A1 haplotypes associated with reduced glucuronidation and increased serum bilirubin in irinotecan-administered Japanese patients with cancer. Clin Pharmacol Therapeut. 2004;75:501-15.

42. Innocenti F, Liu W, Chen P, et al. Haplotypes of variants in the UDPglucuronosyltransferase1A9 and 1A1 genes. Pharmacogen Genom. 2005;15: 295-301.

43. Han JY, Lim HS, Shin ES, et al. Comprehensive analysis of UGT1A polymorphisms predictive for pharmacokinetics and treatment outcome in patients with non-small-cell lung cancer treated with irinotecan and cisplatin. J Clin Oncol. 2006;24:2237-44.

\section{Publisher's Note}

Springer Nature remains neutral with regard to jurisdictional claims in published maps and institutional affiliations.
Ready to submit your research? Choose BMC and benefit from:

- fast, convenient online submission

- thorough peer review by experienced researchers in your field

- rapid publication on acceptance

- support for research data, including large and complex data types

- gold Open Access which fosters wider collaboration and increased citations

- maximum visibility for your research: over $100 \mathrm{M}$ website views per year

At BMC, research is always in progress.

Learn more biomedcentral.com/submissions 